\title{
Effects of Zinc and Calcium Concentration on the Microstructure and Mechanical Properties of Hot-Rolled Mg-Zn-Ca Sheets
}

\author{
Jun Luo ${ }^{1,2} \cdot$ Hong Yan $^{1} \cdot$ Nan Zheng ${ }^{1} \cdot$ Rong-Shi Chen ${ }^{1}$
}

Received: 2 September 2015/Revised: 11 November 2015/Published online: 8 February 2016

(C) The Chinese Society for Metals and Springer-Verlag Berlin Heidelberg 2016

\begin{abstract}
Four kinds of $\mathrm{Mg}$ alloys with different $\mathrm{Zn}$ and $\mathrm{Ca}$ concentration were selected to analyze the effect of $\mathrm{Zn}$ and $\mathrm{Ca}$ concentration on the microstructure and the mechanical properties of $\mathrm{Mg}-\mathrm{Zn}-\mathrm{Ca}$ alloys. It was found that $\mathrm{Zn}$ and $\mathrm{Ca}$ concentration has a great influence on the volume fraction, the morphology and the size of second phase. The $\mathrm{Mg}-1.95 \mathrm{Zn}-$ $0.75 \mathrm{Ca}(\mathrm{wt} \%)$ alloy with the highest volume fraction, continuous network and largest size of $\mathrm{Ca}_{2} \mathrm{Mg}_{6} \mathrm{Zn}_{3}$ phase showed the lowest elongation to failure of about $7 \%$, while the $\mathrm{Mg}-0.73 \mathrm{Zn}-0.12 \mathrm{Ca}$ (wt\%) alloy with the lowest volume fraction and smallest size of $\mathrm{Ca}_{2} \mathrm{Mg}_{6} \mathrm{Zn}_{3}$ phase showed the highest elongation to failure of about $37 \%$. It was suggested that uniform elongations of the $\mathrm{Mg}-\mathrm{Zn}-\mathrm{Ca}$ alloys were sensitive to the volume fraction of the $\mathrm{Ca}_{2} \mathrm{Mg}_{6} \mathrm{Zn}_{3}$ phases, especially the network $\mathrm{Ca}_{2} \mathrm{Mg}_{6} \mathrm{Zn}_{3}$ phases; post-uniform elongations were dependent on the size of the $\mathrm{Ca}_{2} \mathrm{Mg}_{6} \mathrm{Zn}_{3}$ phase, especially the size of network $\mathrm{Ca}_{2} \mathrm{Mg}_{6} \mathrm{Zn}_{3}$ phase. Reduction in $\mathrm{Zn}$ and $\mathrm{Ca}$ concentration was an effective way to improve the roomtemperature ductility of weak textured $\mathrm{Mg}-\mathrm{Zn}-\mathrm{Ca}$ alloys.
\end{abstract}

KEY WORDS: Mg-Zn-Ca alloys; Ductility; Hot rolling; Texture; Second phase

\section{Introduction}

$\mathrm{Mg}$ alloys are the attractive materials for weight reduction in automotive and 3C (computer, communications, consumer electronics) applications [1, 2]. However, the main challenges for the applications of $\mathrm{Mg}$ sheets are their low ductility and poor formability at room temperature. Extensive investigations [3-9] have been carried out to

Available online at http://link.springer.com/journal/40195

Hong Yan

hyan@imr.ac.cn

$\bowtie$ Rong-Shi Chen

rschen@imr.ac.cn

1 The Group of Magnesium Alloys and Their Applications, Institute of Metal Research, Chinese Academy of Sciences, Shenyang 110016, China

2 University of Chinese Academy of Sciences, Beijing 100049, China explore the reason for the poor ductility of $\mathrm{Mg}$ sheets, and it was found that poor ductility is mainly attributed to the existence of strong basal texture. Recently, it has been reported that addition of rare earth (RE) elements can weaken the basal texture of $\mathrm{Mg}$ sheets, and obtain nonbasal texture, which were typically characterized by the weakening peak intensity as well as the broadening of basal poles along the transverse direction (TD) $[6,10,11]$. This kind of texture was beneficial to the operation of basal slip, and promoting $\{10-12\}$ tension twinning tendency, consequently resulting in an improvement of room-temperature ductility [12].

In addition to the $\mathrm{RE}$ elements, calcium $(\mathrm{Ca})$ is another element, which can modify texture of Mg alloys [13-24]. Some researchers [21-23] reported that the extruded $\mathrm{Mg}-$ Ca binary alloys exhibited the "rare earth" texture component. However, Zeng et al. [25] indicated that the Ca addition did not cause any texture weakening effect in $\mathrm{Mg}-$ $\mathrm{Zn}-\mathrm{Ca}$ alloy during cold rolling and it only delayed the development of a strong basal texture by reducing the 
growth of deformation twins. Recently, Bohlen et al. [24] observed the texture modification during annealing of two hot-rolled $\mathrm{Mg}-\mathrm{Zn}-\mathrm{Ca}$ alloys and suggested that the texture weakening effect was connected with the different recrystallization mechanisms. Thus, the texture weakening mechanism of $\mathrm{Ca}$ element in $\mathrm{Mg}$ alloys was complex. Up to now, two probable mechanisms have been proposed: One is the particle stimulated nucleation (PSN) mechanism caused by the Ca-containing second phase [14, 26], and the other is the decrease of stacking fault energy (SFE) as well as the reduction of $c / a$ ratio caused by the solute $\mathrm{Ca}$ atoms in $\mathrm{Mg}$ matrix [19, 20, 22, 27-30]. However, the above two mechanisms were still not the intrinsic reasons of the texture weakening of the $\mathrm{Mg}-\mathrm{Ca}$ series alloys. Anyhow, it is widely accepted that $\mathrm{Mg}-\mathrm{Zn}-\mathrm{Ca}$ sheets illustrated weak non-basal texture with the texture peaks tilted toward TD after recrystallization annealing $[15,16,18,20,24]$. Moreover, the element $\mathrm{Ca}$ is much cheaper than $\mathrm{RE}$ and it is attractive to replace $\mathrm{RE}$ element with $\mathrm{Ca}$ in $\mathrm{Mg}$ alloy. However, unlike the $\mathrm{Mg}-\mathrm{Zn}-\mathrm{RE}$ alloys, the $\mathrm{Mg}-\mathrm{Zn}-\mathrm{Ca}$ alloys did not show the as-expected excellent room-temperature ductility although they also displayed weak nonbasal textures similar to that of the $\mathrm{Mg}-\mathrm{Zn}-\mathrm{RE}$ alloys and even presented much lower texture intensity [17-19]. Furthermore, the ductility of the reported $\mathrm{Mg}-\mathrm{Zn}-\mathrm{Ca}$ alloys exhibited much variability. For example, the $\mathrm{Mg}-$ $1.0 \mathrm{Zn}-1.0 \mathrm{Ca}$ alloy showed poor elongation to failure only about $12.3 \%$ [17]; the $\mathrm{Mg}-0.5 \mathrm{Zn}-0.1 \mathrm{Ca}$ displayed moderate elongation to failure of $29 \%$ [16], while the $\mathrm{Mg}-1.0 \mathrm{Zn}$ $0.5 \mathrm{Ca}$ alloy and $\mathrm{Mg}-1.0 \mathrm{Zn}-0.2 \mathrm{Ca}$ alloy demonstrated good elongation to failure of $44 \%$ and $35 \%$, respectively [13, 14]. It seems that the ductility of the $\mathrm{Mg}-\mathrm{Zn}-\mathrm{Ca}$ serial alloys not only depended on the texture, but also related to the concentration of $\mathrm{Zn}$ and $\mathrm{Ca}$ elements. Up to now, the reason for this remained unclear and less attention has been paid. Therefore, in the present study, four kinds of $\mathrm{Mg}-\mathrm{Zn}-$ $\mathrm{Ca}$ alloys with different $\mathrm{Zn}$ and $\mathrm{Ca}$ concentration were designed to investigate the effects of $\mathrm{Zn}$ and $\mathrm{Ca}$ concentration on the microstructure and the mechanical properties of $\mathrm{Mg}-\mathrm{Zn}-\mathrm{Ca}$ alloys, aiming at providing a guideline for exploiting high-ductile $\mathrm{Mg}-\mathrm{Zn}-\mathrm{Ca}$ sheets.

\section{Experimental}

Commercial pure magnesium, zinc and $\mathrm{Mg}-30 \mathrm{wt} \% \mathrm{Ca}$ master alloys were loaded into a heat-resistance mild steel crucible to prepare the as-cast $\mathrm{Mg}-\mathrm{Zn}-\mathrm{Ca}$ ingots. The chemical compositions were analyzed using inductively coupled plasma atomic emission spectroscopy (ICP-AES), and the results are listed in Table 1 . Hereafter, the $\mathrm{Mg}-$ $1.95 \mathrm{Zn}-0.75 \mathrm{Ca}, \mathrm{Mg}-1.95 \mathrm{Zn}-0.22 \mathrm{Ca}, \mathrm{Mg}-0.76 \mathrm{Zn}-0.27 \mathrm{Ca}$
Table 1 Analyzed chemical composition of the investigated alloys (wt\%)

\begin{tabular}{llll}
\hline Alloy & Zn & Ca & Mg \\
\hline ZX208 & 1.95 & 0.75 & Bal \\
ZX203 & 1.95 & 0.22 & Bal \\
ZX103 & 0.76 & 0.27 & Bal \\
ZX101 & 0.73 & 0.12 & Bal \\
\hline
\end{tabular}

and $\mathrm{Mg}-0.73 \mathrm{Zn}-0.12 \mathrm{Ca}$ alloys are termed as the ZX208, ZX203, ZX103 and ZX101 alloys, respectively. All the ingots were homogenized at $400{ }^{\circ} \mathrm{C}$ for $10 \mathrm{~h}$ and then quenched in hot water, and then machined in slabs with the dimension of $150 \mathrm{~mm} \times 80 \mathrm{~mm} \times 16 \mathrm{~mm}$. The ZX208 and ZX203 alloys were only rolled to the sheets with a final thickness of $6 \mathrm{~mm}$ after six passes due to serious edge cracking, while the ZX103 and ZX101 alloys could be further rolled to the sheets with a final thickness of $2.2 \mathrm{~mm}$ after additional three passes. During the first six passes, the reduction per pass was about $10 \%-20 \%$ and the rolling temperature was controlled around $320-350{ }^{\circ} \mathrm{C}$. The reduction per pass increased to $20 \%-30 \%$ and the rolling temperature decreased to $300-310{ }^{\circ} \mathrm{C}$ during the additional three passes performed in the ZX103 and ZX101 alloys. After each pass, the rolled specimens were reheated to the rolling temperature and held for $15 \mathrm{~min}$. Finally, all the rolled sheets were annealed at $350{ }^{\circ} \mathrm{C}$ for $1 \mathrm{~h}$.

The samples for optical microstructures observation were etched with acetic picral solution $(2 \mathrm{~g}$ picric acid $+5 \mathrm{ml}$ acetic acid $+5 \mathrm{ml}$ of water $+25 \mathrm{ml}$ ethanol) for $15 \mathrm{~s}$. The volume fractions and the sizes of second phase were measured through the image $\mathrm{J}$ software. Macrotexture measurement was conducted at the midthickness of the RD-TD (rolling direction-transverse direction) planes. Three incomplete pole figures, $\{0002\}$, $\{10-10\}$ and $\{10-11\}$, were measured using an X-ray diffractometer (Bruker D8 DISCOVER) with $\mathrm{CuK} \alpha$ radiation. Complete pole figures were calculated with the DIFFRAC plus TEXEVAl software using the above incomplete pole figures. The phases were analyzed by a scanning electron microscope (SEM, Philips XL30 ESEMFEG/EDAX) equipped with an energy-dispersive X-ray (EDX) spectroscopy analysis system and identified by $\mathrm{X}$-ray diffraction using a monochromatic $\mathrm{Cu} K \alpha$ radiation. Electron back-scattered diffraction (EBSD) was performed on the scanning electron microscope equipped with OIM5.2 software.

Tensile tests were conducted at an initial strain rate of $10^{-3} \mathrm{~s}^{-1}$ at room temperature for the specimens with a gauge length of $10 \mathrm{~mm}$, width of $3.5 \mathrm{~mm}$ and thickness of $2 \mathrm{~mm}$. Three tensile specimens were used to ensure the reproducibility of the data. Considering the textures of $\mathrm{Mg}-$ 
Zn-Ca sheets were usually tilted toward TD [15-18] and the tensile ductility along TD was better than RD under this texture condition $[6,15-18]$, only the tensile ductility along the TD the rolled sheets was evaluated in this paper.

\section{Results}

\subsection{Microstructure and Texture}

Figure 1 shows the optical microstructures of the annealed ZX208, ZX203, ZX103 and ZX101 alloys. All of them possessed fully recrystallized microstructures, as shown in Fig. 1a-d, and the average grain sizes were about 22, 25, 18 and $31 \mu \mathrm{m}$, respectively. Many second phases with black contrast can be detected in the optical microstructures in all alloys. The phases existed mainly in three types of morphologies, granular, network and string. Plenty of continuous network second phase elongated along RD, and uniformly distributed granular particles were found in the ZX208 alloy. Owning to the decrease of Ca concentration, the ZX203 alloy displayed a few semi-continuous network second phase and granular particles. Unlike the ZX203 alloy, the ZX103 alloy displayed string of second phase rather than semi-continuous network one, which means that decreasing $\mathrm{Zn}$ concentration could tailor the morphology of second phase. The ZX101 alloy demonstrated the fewest amount of second phase due to the lowest $\mathrm{Zn}$ and $\mathrm{Ca}$ concentration. However, a few strings of second phase still can be discerned. Figure 2 presents the SEM images of the four kinds of alloys. Figure 2a-d shows the second phase under a low magnification. It can be found that the volume fraction of second phase decreased gradually from the ZX208 alloy to the ZX101 alloy. Figure 2e-h shows the second phase under a higher magnification. It can be discerned that the average sizes of the $\mathrm{Ca}_{2} \mathrm{Mg}_{6} \mathrm{Zn}_{3}$ decreased with the reduction in the $\mathrm{Zn}$ and $\mathrm{Ca}$ concentration. The second phase was confirmed to be the $\mathrm{Ca}_{2} \mathrm{Mg}_{6} \mathrm{Zn}_{3}$ phase by EDX of SEM. Therefore, it was suggested that $\mathrm{Zn}$ and $\mathrm{Ca}$ concentration could affect the morphology, the volume fraction and the size of second phase in the $\mathrm{Mg}-\mathrm{Zn}-\mathrm{Ca}$ alloys.

The (0002) pole figures of the four kinds of alloys are shown in Fig. 3. The ZX208 and ZX203 alloys showed typical non-basal textures with two peaks tilted toward TD, and the intensities of the two peaks were different from each other. It is seen that one is stronger than another, as shown in Fig. 3a, b, respectively. However, the ZX103 and ZX101 alloys showed the textures with four peaks and three peaks tilted toward both RD and TD, as shown in Fig. 3c, d, respectively. Different from the ZX208 and X203 alloys, the intensities of the two TD-tilting peaks in ZX103 alloy were close to each other. Moreover, the ZX103 alloy demonstrated the lowest texture intensity as compared to the other three alloys. According to the peak texture intensities of the four alloys, it can be found that $\mathrm{Ca}$
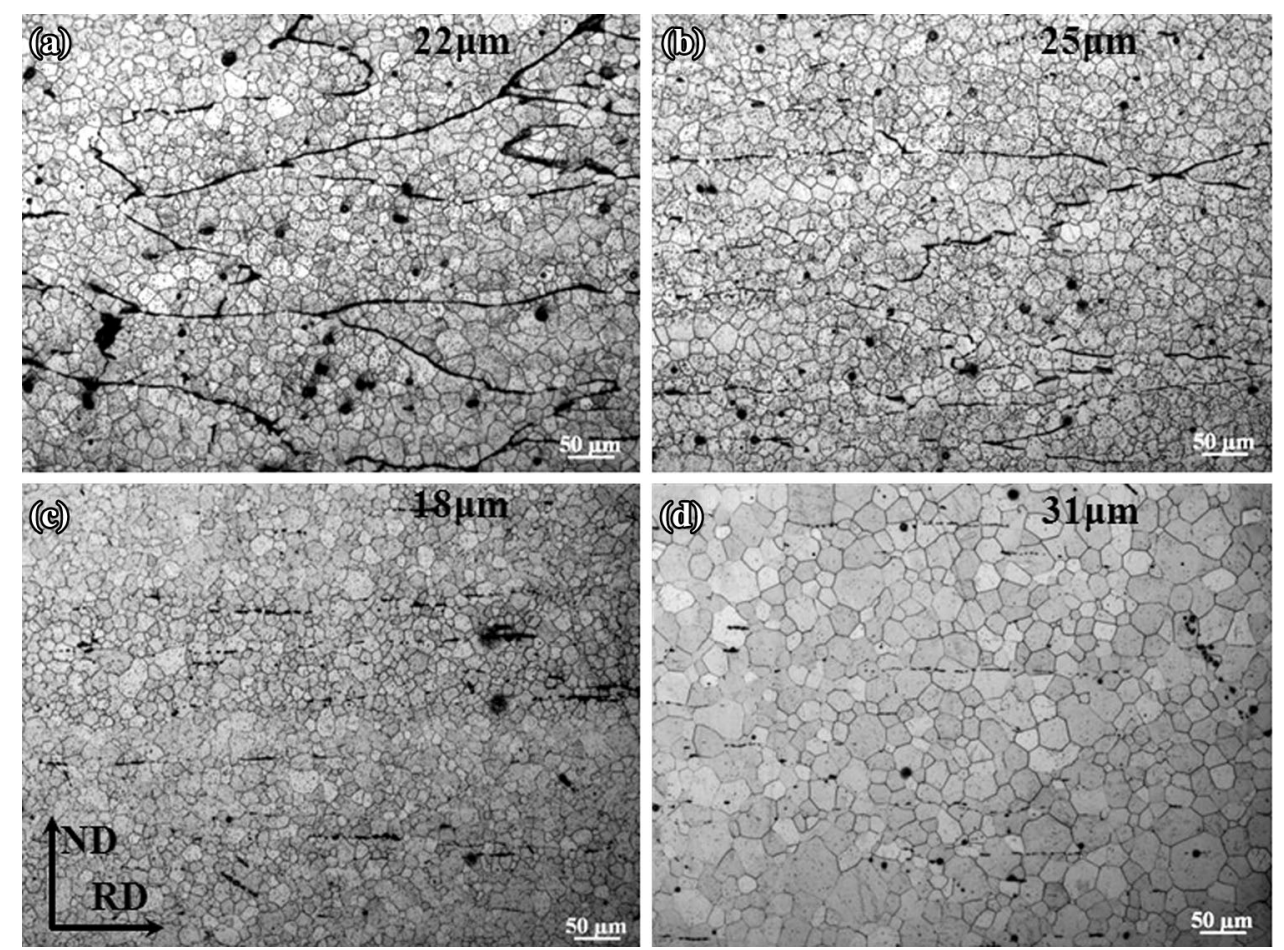

Fig. 1 Optical microstructures of the ZX208 alloy a, ZX203 alloy b, ZX103 alloy c, ZX101 alloy d annealed at $350{ }^{\circ} \mathrm{C}$ for $1 \mathrm{~h}$, respectively 

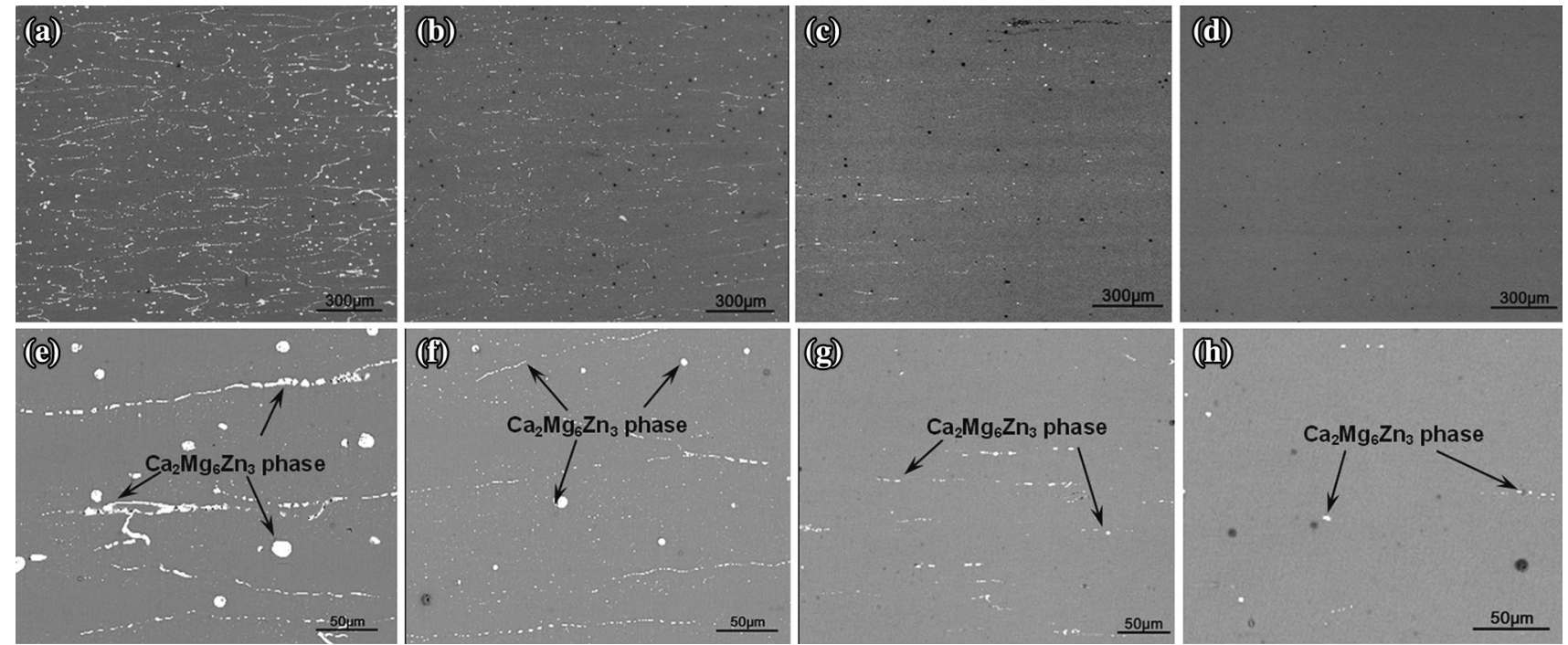

Fig. 2 SEM microstructures of the ZX208 alloy a, e, ZX203 alloy b, f, ZX103 alloy c, g, ZX101 alloy d, h annealed at $350{ }^{\circ} \mathrm{C}$ for $1 \mathrm{~h}$, respectively

(a)
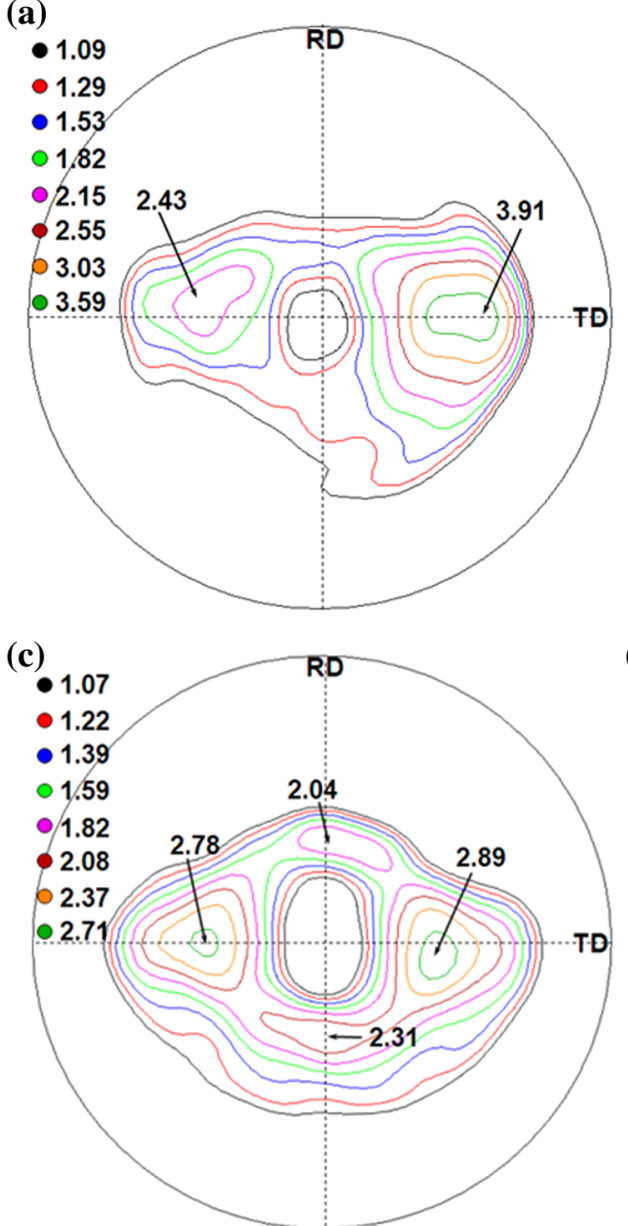

(b)

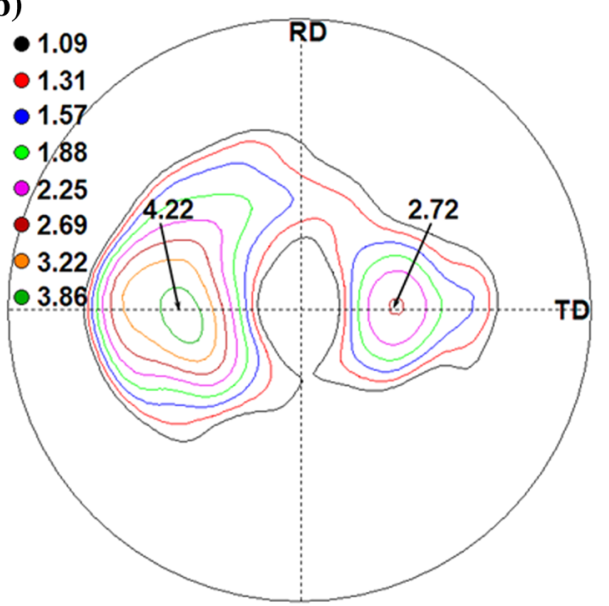

(d)

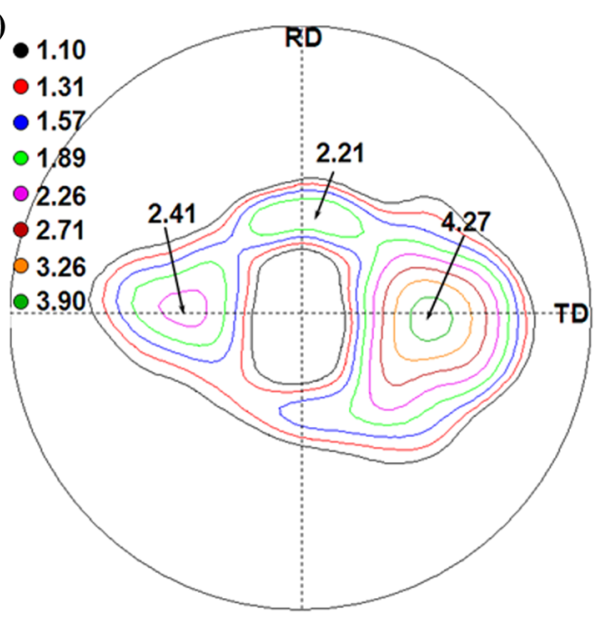

Fig. 3 (0002) Pole figures of the ZX208 a, ZX203 b, ZX103 c, ZX101 d alloys annealed at $350{ }^{\circ} \mathrm{C}$ for 1 h, respectively 
concentration affected the peak intensity of the textures and they decreased with the increase in Ca concentration. This observation was consistent with the results reported by Zhang et al. [14] and Lee et al. [29]. Considering that the ZX101 alloy presented much fewer amount of second phase than the ZX203 alloy and they both exhibited weak textures with similar intensities, it was suggested that the effect of $\mathrm{Ca}$ on texture weakening mainly comes from the presence of $\mathrm{Ca}$ atoms in the $\alpha-\mathrm{Mg}$ solid solution matrix rather than from the Ca-containing second phase. It is worth noting that the tilting angles of the texture peaks toward TD in the studied alloys were about $40^{\circ}$, which was close to the titling angle of $42^{\circ}$ observed in $\mathrm{Mg}-\mathrm{Zn}-\mathrm{Gd}$ alloys [11].

Figure 4 presents the EBSD results of the annealed ZX101 alloy. The inverse pole figure (IPF) map and microtexture are shown in Fig. 4a, b, respectively. It can be found that the ZX101 alloy obtained a nearly fully recrystallized microstructure after the annealing treatment. The microtexture was well consistent with the macrotexture (see Fig. 3d), with basal poles tilted toward both RD and TD, as shown in Fig. 4b. Figure 4c shows the Schmid factor for basal slip during uniaxial tensile test along TD. The average Schmid factor was about 0.33 , meaning that basal slip was favorable during tensile deformation.

\subsection{Tensile Properties}

The typical engineering strain and stress tensile curves of the alloys are displayed in Fig. 5a. The ZX203 and ZX103 alloys both showed the highest ultimate tensile strength (UTS), about $210 \mathrm{MPa}$; the ZX101 alloy presented the moderate UTS, about $200 \mathrm{MPa}$; and the ZX208 alloy illustrated the lowest UTS, about $175 \mathrm{MPa}$. The $0.2 \%$ yield strength of the four alloys was about 99, 80, 107 and $72 \mathrm{MPa}$, for the ZX208, ZX203, ZX103 and ZX101 alloys, respectively. The most evident difference of the four alloys was the elongation to failure. The ZX101 alloy exhibited the highest elongation to failure of about $37 \%$, while the ZX208 alloy displayed the lowest elongation to failure of about $7 \%$, which means that the elongation to failure gradually increases with the decrease of $\mathrm{Zn}$ and $\mathrm{Ca}$ concentration in the present study. To analyze the effect of $\mathrm{Zn}$ and $\mathrm{Ca}$ concentration on the elongations to failure $\left(E_{\mathrm{f}}\right)$ in detail, the uniform elongations $\left(E_{\mathrm{u}}\right)$ and post-uniform elongations $\left(E_{\mathrm{pu}}\right)$ were measured separately, as shown in Fig. 5b. It can be seen that the uniform elongation firstly increased sharply from about $7 \%$ of the ZX208 alloy to $21 \%$ of the ZX203 alloy and then increased slowly from $24 \%$ of the ZX103 alloy to $25 \%$ of the ZX101 alloy. On the contrary, the postuniform elongation showed the opposite tendency: It firstly increased slowly from nearly zero of the ZX208 alloy to about 5\% of the ZX103 alloy and then increased obviously to about $12 \%$ of the ZX101 alloy. It was noteworthy that the ZX208 alloy showed the similar texture and the grain size to the ZX203 alloy, but the latter alloy displayed higher uniform elongation; the ZX103 alloy presented the smaller grain size, but it exhibited much lower post-uniform elongation compared with that of the ZX101 alloy. Figure 5c illustrates the relationship between the elongation to failure and the $\mathrm{Zn}$ and $\mathrm{Ca}$ concentration. It can be discerned that the elongation to failure was increased with the decrease of the $\mathrm{Zn}$ and $\mathrm{Ca}$ concentration indeed. It was worth to mention that the ZX101 alloy in the present study exhibited the highest elongation to failure in the reported $\mathrm{Mg}-\mathrm{Zn}-\mathrm{Ca}$ alloys excepting the extruded ones.
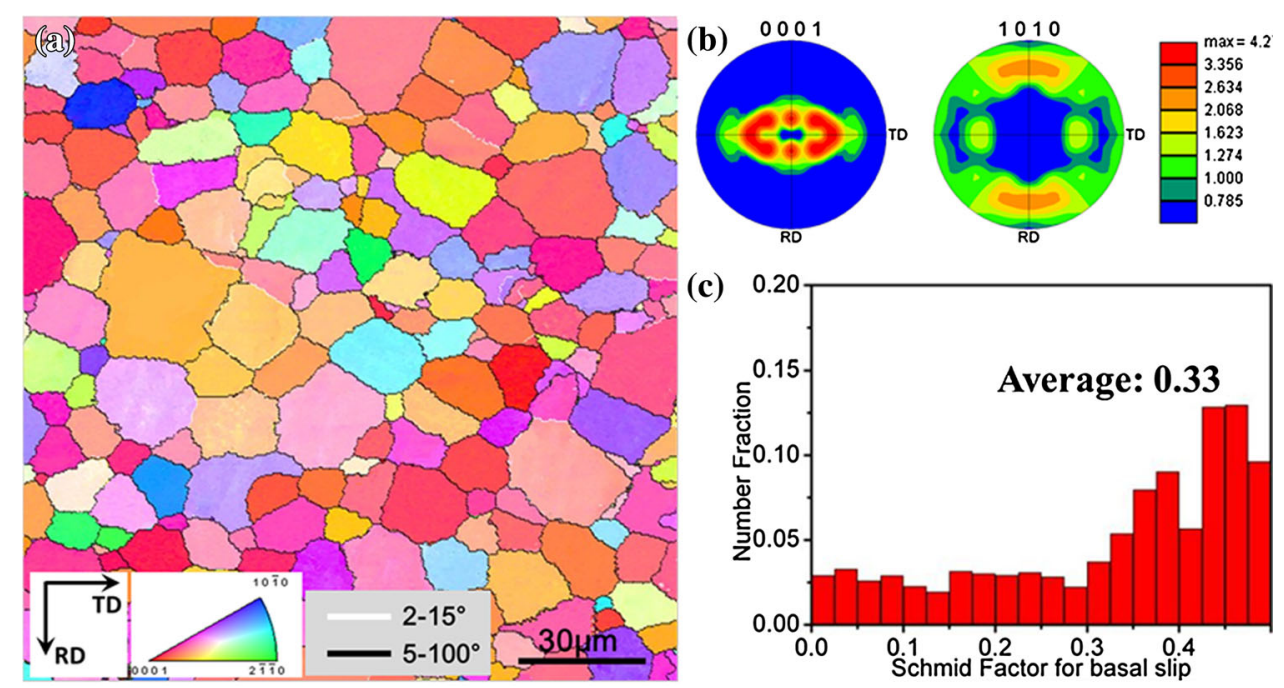

(c)

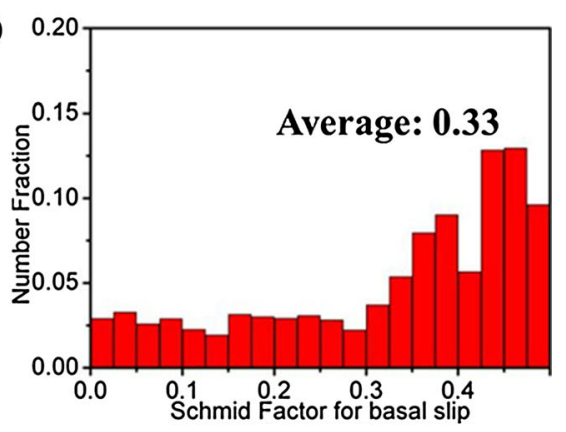

Fig. 4 Inverse pole figure a, microtexture b, Schmid factor for basal slip c of the ZX101 alloy annealed at $350{ }^{\circ} \mathrm{C}$ for $1 \mathrm{~h}$ 

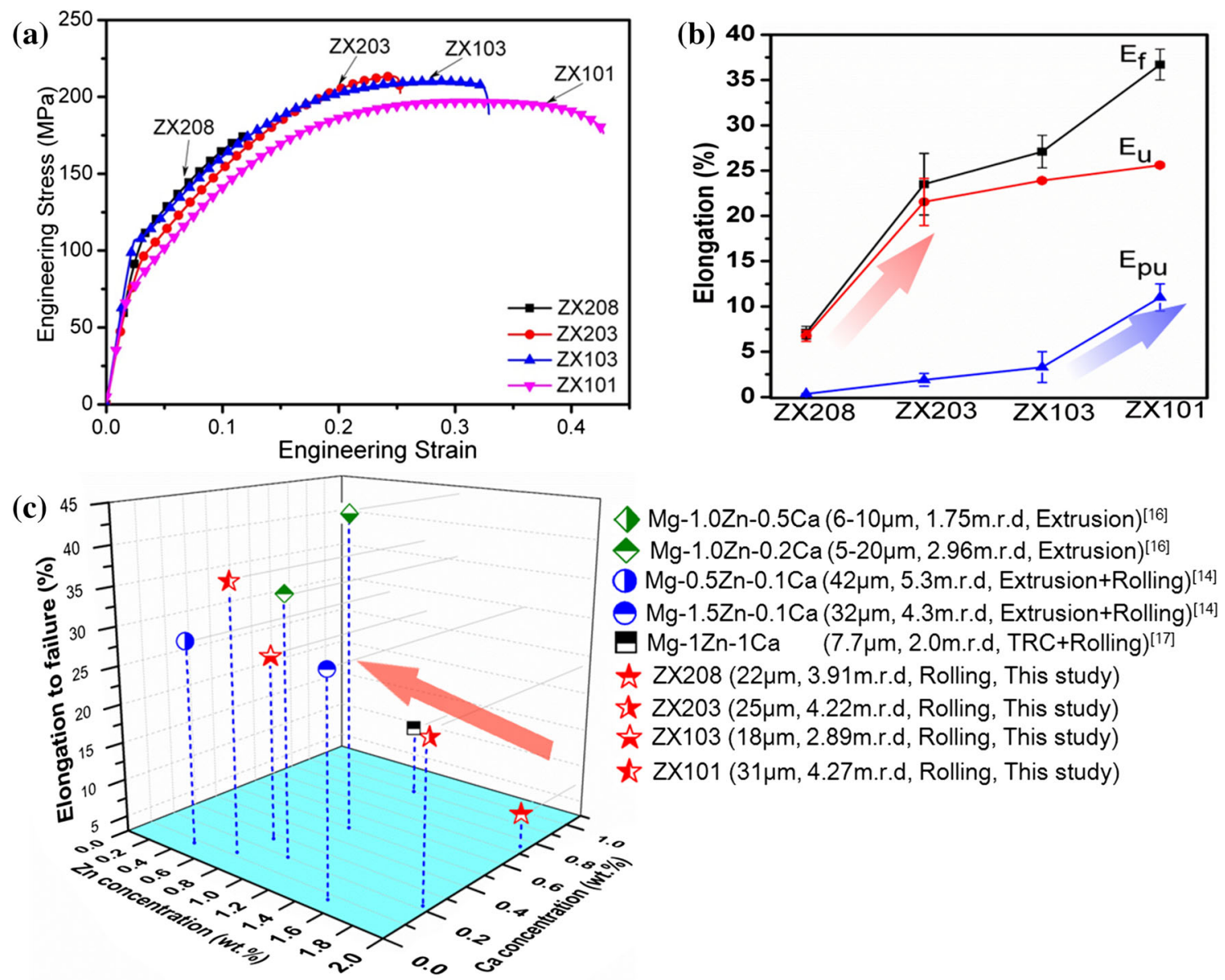

Fig. 5 Typical engineering stress-strain curves a; elongation to failure $\left(E_{\mathrm{f}}\right)$, uniform elongation $\left(E_{\mathrm{u}}\right)$ and post-uniform elongation $\left(E_{\mathrm{pu}}\right)$ of the studied alloys $\mathbf{b}$; the relationship between elongation to failure and $\mathrm{Zn}$ and $\mathrm{Ca}$ concentration of the $\mathrm{Mg}-\mathrm{Zn}-\mathrm{Ca}$ alloys $\mathbf{c}$
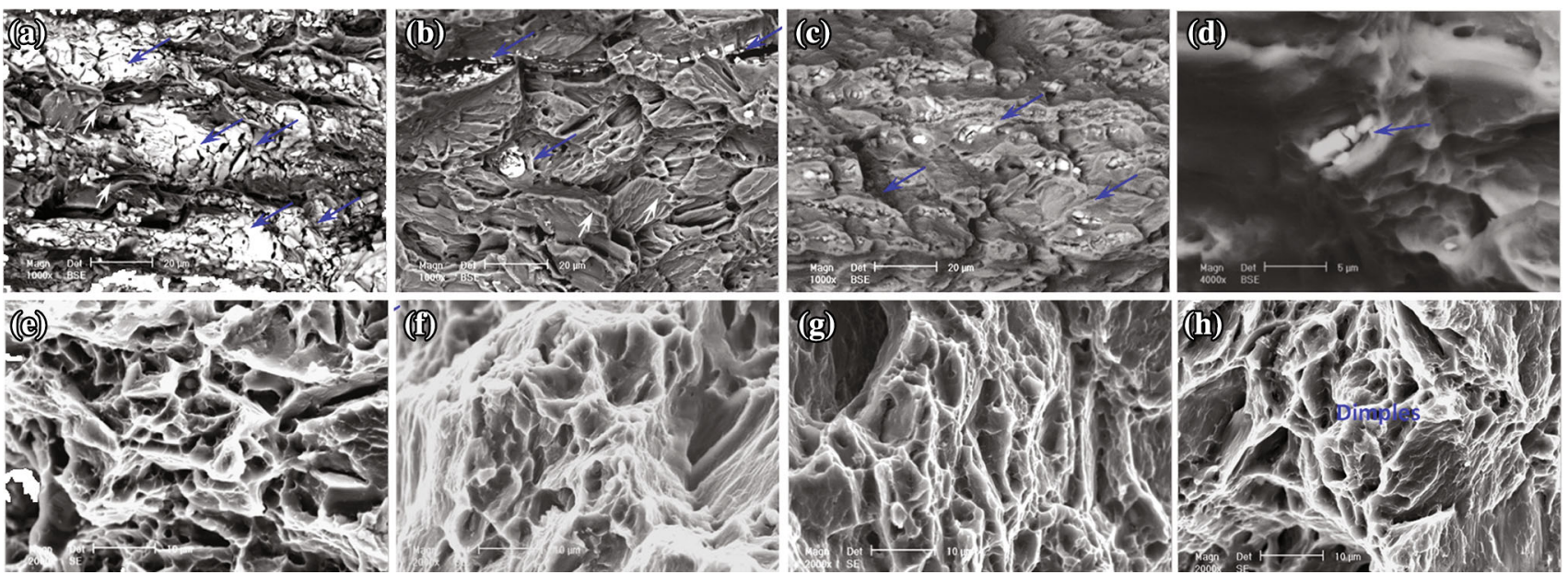

Fig. 6 Fracture morphologies of tensile tested samples: a, e ZX208, b, f ZX203, c, g ZX103, d, h ZX101 alloys 


\subsection{Fracture Analysis}

Figure 6 displays the SEM images of the fracture morphologies of the four alloys. Plenty of broken second phases were observed on the fracture surface of all the alloys, as shown in Fig. 6a-d. This indicated that the second-phase particles presented in the alloys were brittle and they were easy to be fractured during the tensile deformation. Moreover, large numbers of severely fractured second-phase particles were found in the ZX208 and ZX203 alloys due to the higher volume fraction and larger size of second-phase particles in their microstructure, which originated from their higher $\mathrm{Zn}$ and $\mathrm{Ca}$ concentration. Large cleavage planes can be seen in both the ZX208 and ZX203 alloys (indicated by the white arrows in Fig. 6a, b), while no such cleavage planes were observed in the ZX101 alloy. In addition, many microcracks can be detected connecting the second-phase particles of the ZX208, ZX203 and ZX103 alloys, while there are few ones in the ZX101 alloy. Figure 6e, f shows the secondary electron images of the fracture surfaces of the four alloys. Deep plastic dimples and tearing ridges can be observed in all alloys, indicating that the $\alpha-\mathrm{Mg}$ matrix is prone to take place plastic deformation during the uniaxial tensile test. According to the above different fracture surface topographies, it was suggested that the fracture mechanisms was quasi-cleavage transgranular fracture in the ZX208 alloy while ductile fracture in the ZX101 alloy.

The backscattered electron images taken from the sheet surfaces of the tensile tested samples are shown in Fig. 7. Figure 7a-d displays the microstructure of the four alloys near the fracture surface under a low magnification. It can be found that cracks nucleated at larger continuous network phase and propagated along them (indicated with white arrows) in both ZX208 and ZX203 alloys, as shown in Fig. $7 \mathrm{a}, \mathrm{b}$. Figure $7 \mathrm{c}$ shows a broken string phase in the ZX103 alloy and a large granular phase. A few broken granular phases were detected in the ZX101 alloy (Fig. 7d). Figure 7e, f illustrates the cracks propagated along the network phases in both ZX208 and ZX203 alloys under the higher magnification. Figure $7 \mathrm{~g}$ shows a broken string phase near the fracture surface, and obvious cracks can be discerned in those phase. The inset in Fig. $7 \mathrm{~g}$ shows that the cracks nucleated in a broken granular phase and propagated into the matrix, as indicated with white arrows. Figure $7 \mathrm{~h}$ shows a broken granular phase in the ZX101 alloy. However, those cracks did not propagate into the matrix. The broken second phases indicated by arrows A, B and $\mathrm{C}$ in Fig. $7 \mathrm{a}-\mathrm{c}$ were identified as $\mathrm{Ca}_{2} \mathrm{Mg}_{6} \mathrm{Zn}_{3}$ according to the results of EDX analysis.

\section{Discussion}

\subsection{Effects of $\mathrm{Zn}$ and Ca Concentration on the Volume Fraction, the Morphology and the Size of Second Phase}

There are many types of second phases, mainly $\mathrm{Mg}_{2} \mathrm{Ca}$ and $\mathrm{Ca}_{2} \mathrm{Mg}_{6} \mathrm{Zn}_{3}$ phases, in the $\mathrm{Mg}-\mathrm{Zn}-\mathrm{Ca}$ alloys [17, 31-33]. A simply criterion introduced by Zhang and Yang [33] was that the phase constitution of $\mathrm{Mg}-\mathrm{Zn}-\mathrm{Ca}$ alloys was mainly controlled by the atomic ratio of $\mathrm{Zn}$ to $\mathrm{Ca}$. When the ratio was larger than 1.2, the alloy was mainly composed of primary $\mathrm{Mg}$ and eutectic microstructure $\left(\alpha-\mathrm{Mg}+\mathrm{Ca}_{2}\right.$ $\mathrm{Mg}_{6} \mathrm{Zn}_{3}$ ), while the alloy was composed of primary $\mathrm{Mg}$ and divorced eutectic $\left(\alpha-\mathrm{Mg}+\mathrm{Mg}_{2} \mathrm{Ca}+\mathrm{Ca}_{2} \mathrm{Mg}_{6} \mathrm{Zn}_{3}\right)$ when the atomic ratio was $<1.2$. In the present study, the four alloys all showed the $\mathrm{Zn} / \mathrm{Ca}$ atomic ratio larger than 1.2 and the main second phase was $\mathrm{Ca}_{2} \mathrm{Mg}_{6} \mathrm{Zn}_{3}$ based on the above criterion. This was consistent with the SEM observation (Figs. 2, 7). Thus, it can be predicted that the second phase mainly be the $\mathrm{Ca}_{2} \mathrm{Mg}_{6} \mathrm{Zn}_{3}$ phase although the $\mathrm{Zn}$ and $\mathrm{Ca}$ concentration was decreased.

Based on the microstructure observation, it is suggested that $\mathrm{Zn}$ and $\mathrm{Ca}$ concentration has great influence on the morphology, the volume fraction and the size of $\mathrm{Ca}_{2} \mathrm{Mg}_{6}$ $\mathrm{Zn}_{3}$ phase. For example, the morphologies of the $\mathrm{Ca}_{2}$ $\mathrm{Mg}_{6} \mathrm{Zn}_{3}$ phase are the continuous network and granular for the ZX208 alloy, the semi-continuous network and granular in the ZX203 and the string and granular in both of the ZX103 and ZX101 alloy. The volume fractions of the $\mathrm{Ca}_{2} \mathrm{Mg}_{6} \mathrm{Zn}_{3}$ phase with different morphologies were measured in detail, as shown in Fig. 8a. The total volume fraction of second phase decreased obviously from the ZX208 alloy to the ZX101 alloy due to the decrease of Zn and $\mathrm{Ca}$ concentration. Similar decreasing trend is observed in the volume fraction of network or string phase. However, the volume fraction of the granular phase illustrated a little change, decreasing from about $0.6 \%$ of the ZX208 alloy to about $0.02 \%$ of the ZX101 alloy. The average sizes of the granular phases in the four alloys were evaluated based on five SEM maps obtained from different areas, as shown in Fig. 8b. It can be discerned that the average size of granular phase also decreased with the decrease of $\mathrm{Zn}$ and $\mathrm{Ca}$ concentration, which is similar to the tendency of the volume fraction. Although it is difficult to measure the average size of network or string phase, it can be found that those phase existed in the ZX208 alloy was much larger than the rest alloy (see Figs. 6, 7). Based on the above analysis, it is suggested that both the volume fraction and the size of $\mathrm{Ca}_{2} \mathrm{Mg}_{6} \mathrm{Zn}_{3}$ phase can be decreased by reducing the $\mathrm{Zn}$ and $\mathrm{Ca}$ concentration. 


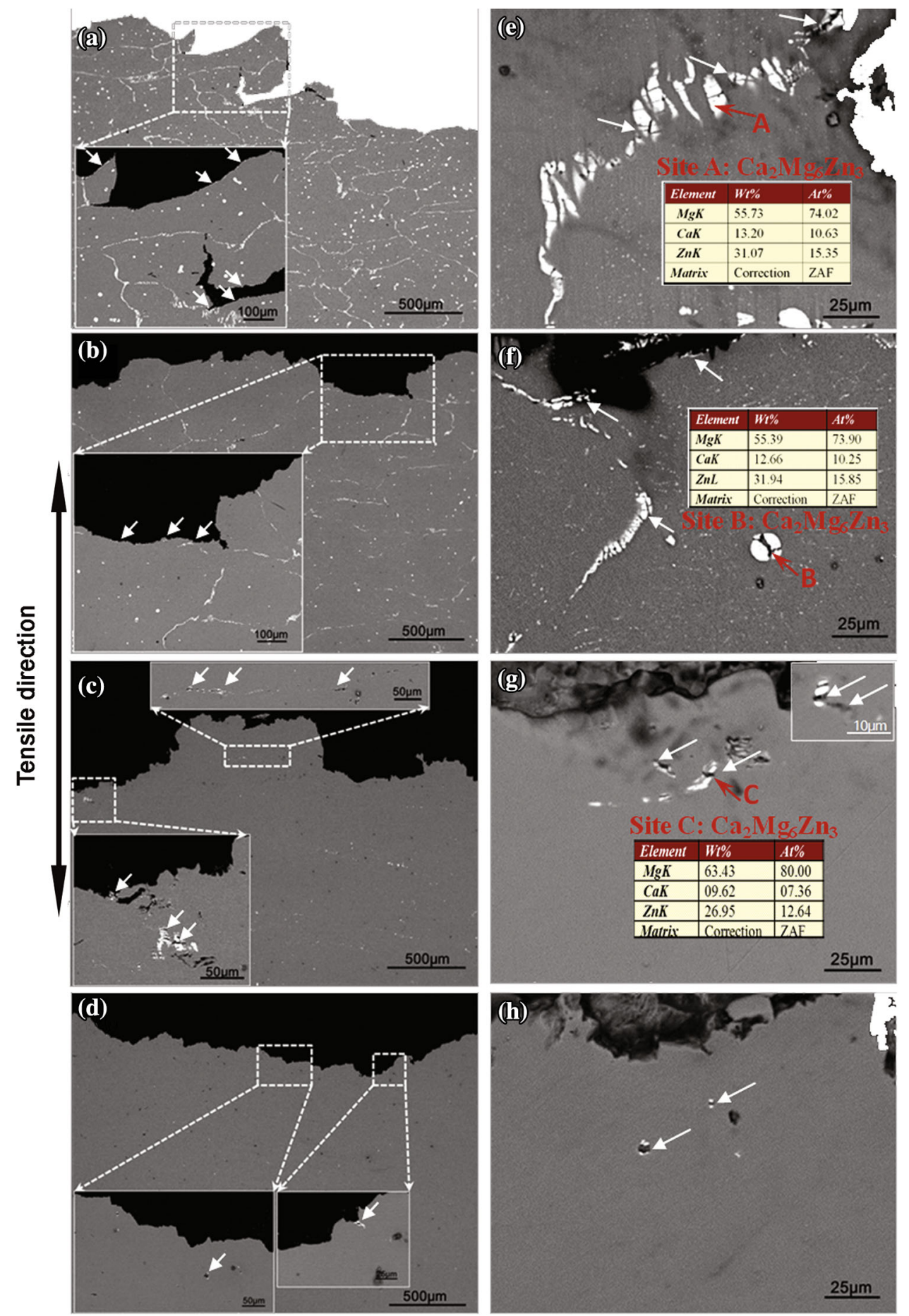

Fig. 7 Backscattered electron images of the sheet surfaces of tensile tested samples: a, e ZX208, b, f ZX203, c, g ZX103, d, h ZX101 alloys, respectively; Corresponding energy-dispersive X-ray spectra of points A, B and C indicated in images e-g

\subsection{Effects of Second Phase on Tensile Ductility}

It is known that the room-temperature tensile ductility of metallic material is mainly influenced by two factors, i.e., the texture and the gain size. Similarly, the tensile ductility of magnesium alloys is also related to the two factors. And many works investigated the influences of the texture and the grain size on the tensile ductility of Mg alloys [5-9, 3436]. Chen et al. [34] revealed that uniform elongation was strongly correlated with the texture, and it increased with basal texture weakening. Yang and Ghosh [35] found that the post-uniform elongation of basal textured AZ31 alloy 
(a)

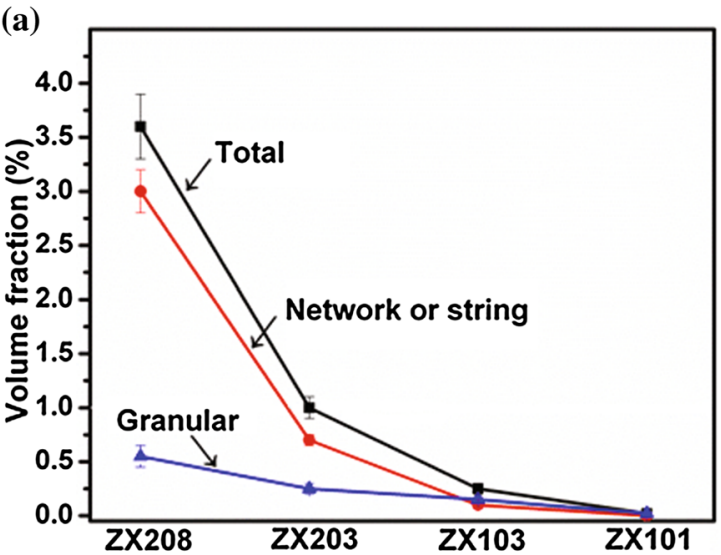

(b) $\widehat{\varepsilon}$

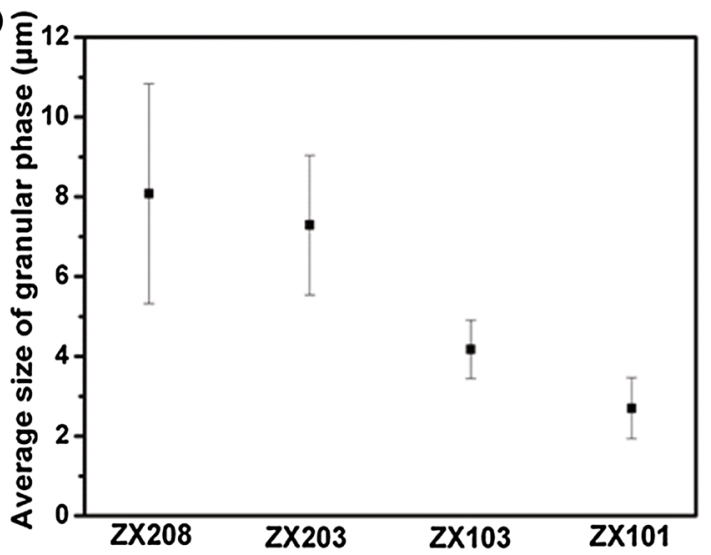

Fig. 8 Volume fractions of the second phase with different morphologies a, the average size of granular phase $\mathbf{b}$ of the studied alloys

was enhanced due to the grain refinement. Wu et al. [36] also indicated that the uniform elongation of different grain-sized GZ31 alloy changed a little due to the similar non-basal texture while the post-uniform elongation decreased obviously with increasing grain size. The main conclusion was that weak texture could improve the uniform elongation and fine grain size could enhance the postuniform elongation.

In this study, all of the $\mathrm{Mg}-\mathrm{Zn}-\mathrm{Ca}$ sheets also exhibit non-basal texture and similar grain size, but they did not show expected elongation. As shown in the results, the ZX208 alloy shows the lowest uniform elongation in the studied alloys although it displays the similar texture intensity for ZX203 and ZX101 alloys; the ZX101 alloy presents the largest grain size, but it exhibits the highest post-uniform elongation compared with the rest alloys (see Figs. 2, 4b). This means that the texture and the grain size are not the essential reasons for the variation of tensile ductility in the ZX208, ZX203, ZX103 and ZX101 alloys. From the microstructures, it can be seen that there are many $\mathrm{Ca}_{2} \mathrm{Mg}_{6} \mathrm{Zn}_{3}$ phases with different morphologies. Thus, second phase is more likely to be responsible for the difference of ductility; i.e., the higher volume fraction and larger size of second phase lead to the lower ductility. Indeed, this phenomenon has been reported in metallic materials [37-39]. Thus, we inferred that the $\mathrm{Ca}_{2} \mathrm{Mg}_{6} \mathrm{Zn}_{3}$ phase may affect the ductility except texture and grain size in the $\mathrm{Mg}-\mathrm{Zn}-\mathrm{Ca}$ alloys, and we would discuss the influence of $\mathrm{Ca}_{2} \mathrm{Mg}_{6} \mathrm{Zn}_{3}$ phase on the uniform and post-uniform elongation, respectively.

The morphology, the volume fraction and the size of second phase are obviously different between $\mathrm{Mg}-\mathrm{Zn}-\mathrm{Ca}$ alloys with different $\mathrm{Zn}$ and $\mathrm{Ca}$ concentration (see Fig. 8). It can be found that the distinct difference between the ZX208 and the ZX203 alloys are the uniform elongation and the volume fraction of second phase, especially the volume fraction of network phase, while the volume fraction and the size of granular phase present a little change (see Figs. 5b, 8a). On the other hand, all of the ZX203, ZX103 and ZX101 alloys show the similar higher uniform elongation due to their lower volume fraction of second phase. Thus, it is indicated that the uniform elongations of the $\mathrm{Mg}-\mathrm{Zn}-\mathrm{Ca}$ alloys are mainly affected by the volume fraction of second phase, especially the network phase.

To confirm the above inference, the work hardening rate curves of the four alloys, as a function of flow stress $(\sigma)$ subtracting the yield strength $\left(\sigma_{0.2}\right)$, were plotted, as shown in Fig. 9. All the hardening rate curves exhibit initially a region of rapidly decreasing $\mathrm{d} \sigma / \mathrm{d} \varepsilon$ with increasing flow stress, which can be attributed to the elastic-plastic transition. Then, a nearly constant hardening rate behavior associated with stage II of work hardening, with $\mathrm{d} \sigma /$ $\mathrm{d} \varepsilon \approx 1050 \mathrm{MPa}$, for all of the four alloys can be detected. It was known that the high uniform elongation was attributed to the higher work hardening rate. Huang et al. [40] suggested that high working hardening rate could result in the high ability against the strain instability and in turn enhanced the uniform elongation. The ZX208 alloy

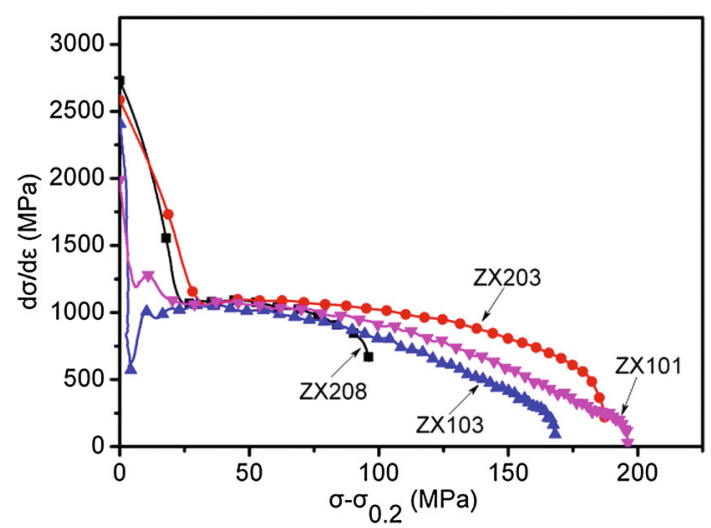

Fig. 9 Work hardening rate curves of the studied alloys 
illustrates a depressed stage II and a rapid decrease of hardening rate even after $\left(\sigma-\sigma_{0.2}\right)=60 \mathrm{MPa}$, while the rest alloys displayed prolonged stage II and delayed decrease of work hardening rate. That is the reason why the ZX208 alloy demonstrates the lowest uniform elongation compared with the rest alloys. According to the fracture images of the ZX208 alloy, it can be found that most of the second phases are full of cracks (see Fig. 6a) and the cracks propagate along the network phase into the internal of the microstructure (see Fig. 7a, e). Kiser et al. [41] indicated that particle cracking could cause local softening, and reduce the work hardening rate. Thus, the rapid decrease of work hardening rate and the lowest uniform elongation of the ZX208 alloy are from the network $\mathrm{Ca}_{2} \mathrm{Mg}_{6} \mathrm{Zn}_{3}$ phase. It is worth noting that although the ZX203 alloy also presents some fractured network $\mathrm{Ca}_{2} \mathrm{Mg}_{6} \mathrm{Zn}_{3}$ phase (see Fig. $7 \mathrm{~b}$, f), it still shows relative higher work hardening rate and uniform elongation. This is mainly due to its lower volume fraction and smaller size of the network $\mathrm{Ca}_{2} \mathrm{Mg}_{6} \mathrm{Zn}_{3}$ phase compared with the ZX208 alloy.

Based on the results in Figs. 5 and 8, it is suggested that the post-uniform elongation is insensitive to the volume fraction of $\mathrm{Ca}_{2} \mathrm{Mg}_{6} \mathrm{Zn}_{3}$ phase, i.e., an obvious decrease of the volume fraction of $\mathrm{Ca}_{2} \mathrm{Mg}_{6} \mathrm{Zn}_{3}$ phase along with a slow increase of post-uniform elongation in the ZX208 and ZX203 alloy. Hence, the distinct increase of post-uniform elongation in the ZX101 alloy is not mainly ascribe to the much lower volume fraction of $\mathrm{Ca}_{2} \mathrm{Mg}_{6} \mathrm{Zn}_{3}$ phase, although it may be favorable for the improvement of postuniform elongation in some extent. By comparing the postuniform elongation and the size of $\mathrm{Ca}_{2} \mathrm{Mg}_{6} \mathrm{Zn}_{3}$ phase in the four alloys, it can be found that the ZX101 alloy with the smallest size of $\mathrm{Ca}_{2} \mathrm{Mg}_{6} \mathrm{Zn}_{3}$ phase showed the highest postuniform elongation. This means that the post-uniform elongations of $\mathrm{Mg}$ alloys related to the size of second phase. Indeed, Shi et al. [39] found that Mg-3Y alloy with large size of second phase displayed lower post-uniform elongation compared with the $\mathrm{Mg}-1 \mathrm{Y}$ alloy; Tanaka et al. [37] suggested that the fracture elongation decreased with the increased size of second-phase particles in the plastically deformed matrix under uniaxial tensile test. Moreover, the ZX208 alloy and ZX203 alloy with larger network $\mathrm{Ca}_{2} \mathrm{Mg}_{6} \mathrm{Zn}_{3}$ phase exhibited lower post-uniform elongations. This observation also agrees with the wellknown conclusion that large network phase can obviously deteriorate ductility in metallic materials $[42,43]$. Therefore, larger size of $\mathrm{Ca}_{2} \mathrm{Mg}_{6} \mathrm{Zn}_{3}$ phase, especially larger network $\mathrm{Ca}_{2} \mathrm{Mg}_{6} \mathrm{Zn}_{3}$ phase, gives rise to a lower postuniform elongation.

It is well known that geometrical instabilities (internal microvoids and microcracks within the gauge section) dominate the plastic response after the onset of necking, and deformation concentrated within the necking regions with the high density of the microvoids/microcracks. Thus, necking may continue until these microvoids and microcracks coalesce; otherwise catastrophic failure occurs when a critical condition is reached [44]. It is noted that the postuniform elongation is observed to the failure point after the onset of necking [45]. Therefore, brittle second phase with microcracks would certainly affect the post-uniform elongation according to the above analysis. Based on the observation of the fracture morphologies of the four $\mathrm{Mg}_{-}$ $\mathrm{Zn}-\mathrm{Ca}$ alloys, it can be found that there are many microcracks in the large-sized network, and granular $\mathrm{Ca}_{2} \mathrm{Mg}_{6} \mathrm{Zn}_{3}$ phases in the ZX208, ZX203 and ZX103 alloy. That's why the above three alloys displayed the lower post-uniform elongation. As for the ZX101 alloy, it also presented some fractured $\mathrm{Ca}_{2} \mathrm{Mg}_{6} \mathrm{Zn}_{3}$ phases (Fig. 6d) but it was difficult for the microcracks to grow into the matrix due to the minimum size of $\mathrm{Ca}_{2} \mathrm{Mg}_{6} \mathrm{Zn}_{3}$ phases, and the damage of $\mathrm{Ca}_{2} \mathrm{Mg}_{6} \mathrm{Zn}_{3}$ phases to the post-uniform elongation could be neglected.

To sum up, brittle $\mathrm{Ca}_{2} \mathrm{Mg}_{6} \mathrm{Zn}_{3}$ phases in $\mathrm{Mg}-\mathrm{Zn}-\mathrm{Ca}$ alloys can affect both uniform and post-uniform elongation: The uniform elongation decreased with increasing volume fraction of the $\mathrm{Ca}_{2} \mathrm{Mg}_{6} \mathrm{Zn}_{3}$ phases, especially the volume fraction of the network $\mathrm{Ca}_{2} \mathrm{Mg}_{6} \mathrm{Zn}_{3}$ phases; the post-uniform elongation decreased with increasing size of the $\mathrm{Ca}_{2} \mathrm{Mg}_{6} \mathrm{Zn}_{3}$ phase, especially the size of the network $\mathrm{Ca}_{2} \mathrm{Mg}_{6} \mathrm{Zn}_{3}$ phases.

\subsection{Yield Strength}

Yield strength of Mg alloys usually can be affected by the grain size [46], the texture [47], the second phase [48] and the solute atoms [49], etc. In the present study, the average grain sizes of the ZX208, ZX203, ZX103 and ZX101 alloys are different from each other and the sequence of the grain size is ZX103 < ZX208 < ZX203 < ZX101. According to the Hall-Petch relationship, the strengthen effect caused by the grain size should be ZX103 $>$ ZX208 $>$ ZX203 $>$ ZX101. Indeed, this sequence is accord with the measured yield strength. The texture peaks of the studied alloys all tilted about $40^{\circ}$ away from ND toward TD, and the peak intensities of them are close to each other. It has been reported that under such a texture condition basal slip and $\{10-12\}$ extension twin were easy to be activated during the tensile testing and they could lead to the relative lower yield strength [12]. Considering the similar texture of the four alloys, it can be inferred that the effect of the grain size on yield strength should be stronger than that of texture. On the other hand, the high amount of the second phase in microstructure can also improve the yield strength of the $\mathrm{Mg}$ alloys since the existence of second-phase particle can inhibit the dislocation movement [48]. The ZX208, ZX203 and ZX103 alloys have much amount of 
$\mathrm{Ca}_{2} \mathrm{Mg}_{6} \mathrm{Zn}_{3}$ phase than the ZX101 alloy (see Fig. 2e-h). Thus, the strengthen effect caused by $\mathrm{Ca}_{2} \mathrm{Mg}_{6} \mathrm{Zn}_{3}$ phase seems to be higher in the ZX208, ZX203 and ZX103 alloys than in the ZX101 alloy. Furthermore, the Zn and Ca solute atoms can also improve the yield strength based on the well-known solid solution strengthening [49]. Considering the $\mathrm{Zn}$ and $\mathrm{Ca}$ solute atoms consumed by the formed plenty of the second phase, the strengthening effect caused by the residual solute atoms might be much lower than that caused by the second phase. Based on the above analysis, it is suggested that the yield strength of $\mathrm{Mg}-\mathrm{Zn}-\mathrm{Ca}$ alloys mainly are affected by the grain size and the second phase in this study. It should be noted that the fine grain-sized ZX103 alloy displays the higher yield strength than the ZX208 alloy, although the former presents much fewer second phase and lower $\mathrm{Zn}$ and $\mathrm{Ca}$ concentration. Therefore, grain refinement is a good way to improve the yield strength of weak textured $\mathrm{Mg}-\mathrm{Zn}-\mathrm{Ca}$ alloys with dilute $\mathrm{Zn}$ and $\mathrm{Ca}$ concentration.

\section{Conclusions}

1. $\mathrm{Zn}$ and $\mathrm{Ca}$ concentration has great influence on the volume fraction, the morphology and the size of second phase in $\mathrm{Mg}-\mathrm{Zn}-\mathrm{Ca}$ alloys. Alloys with lower $\mathrm{Zn}$ and Ca concentration present nearly free of second phase.

2. All of the studied $\mathrm{Mg}-\mathrm{Zn}-\mathrm{Ca}$ alloys show weak nonbasal textures. The peak intensity of the texture decreased with increasing $\mathrm{Ca}$ concentration in the present $\mathrm{Mg}-\mathrm{Zn}-\mathrm{Ca}$ alloys.

3. The ZX101 alloy displayed the highest elongation to failure of about $37 \%$ due to its lowest volume fraction and size of $\mathrm{Ca}_{2} \mathrm{Mg}_{6} \mathrm{Zn}_{3}$ phase compared with the rest alloys. Reduction in $\mathrm{Zn}$ and $\mathrm{Ca}$ concentration was an effective way to improve the room-temperature ductility of the weak textured $\mathrm{Mg}-\mathrm{Zn}-\mathrm{Ca}$ alloys.

4. Uniform elongations of the $\mathrm{Mg}-\mathrm{Zn}-\mathrm{Ca}$ alloys were sensitive to the volume fraction of the $\mathrm{Ca}_{2} \mathrm{Mg}_{6} \mathrm{Zn}_{3}$ phases, especially the network $\mathrm{Ca}_{2} \mathrm{Mg}_{6} \mathrm{Zn}_{3}$ phase; post-uniform elongations were dependent on the size of the $\mathrm{Ca}_{2} \mathrm{Mg}_{6} \mathrm{Zn}_{3}$ phase, especially the size of network $\mathrm{Ca}_{2} \mathrm{Mg}_{6} \mathrm{Zn}_{3}$ phases.

5. Yield strength of the weak textured $\mathrm{Mg}-\mathrm{Zn}-\mathrm{Ca}$ alloys was mainly affected by the grain size and the second phase. Grain refinement is a good way to improve the yield strength of the weak textured $\mathrm{Mg}-\mathrm{Zn}-\mathrm{Ca}$ alloys with dilute $\mathrm{Zn}$ and $\mathrm{Ca}$ concentration in this study.

Acknowledgments This work was financially supported by the National Basic Research Program of China (973 Program, No. 2013CB632202) and the National Natural Science Foundation of China (No. 51301173).

\section{References}

[1] M. Kaseem, B.K. Chung, H.W. Yang, K. Hamad, Y.G. Ko, J. Mater. Sci. Technol. 31, 498 (2015)

[2] D. Sarker, J. Friedman, D.L. Chen, J. Mater. Sci. Technol. 30, 884 (2014)

[3] T. Mukai, M. Yamanoi, H. Watanabe, K. Higashi, Scr. Mater. 45, 89 (2001)

[4] W.J. Kim, C.W. An, Y.S. Kim, S.I. Hong, Scr. Mater. 47, 39 (2002)

[5] J.A. del Valle, F. Carreno, O.A. Ruano, Acta Mater. 54, 4247 (2006)

[6] H. Yan, R.S. Chen, E.H. Han, Mater. Sci. Eng., A 527, 3317 (2010)

[7] D. Wu, R.S. Chen, E.H. Han, J. Alloys Compd. 509, 2856 (2011)

[8] R.K. Sabat, R.K. Mishra, A.K. Sachdev, S. Suwas, Mater. Lett. 153, 158 (2015)

[9] B.Q. Shi, R.S. Chen, W. Ke, J. Magnes, Alloys 1, 210 (2013)

[10] T. Al-Samman, X. Li, Mater. Sci. Eng., A 528, 3809 (2011)

[11] H. Yan, R. Chen, N. Zheng, J. Luo, S. Kamado, E. Han, J. Magnes, Alloys 1, 23 (2013)

[12] H. Yan, S.W. Xu, R.S. Chen, S. Kamado, T. Honma, E.H. Han, J. Alloys Compd. 566, 98 (2013)

[13] B.P. Zhang, L. Geng, L.J. Huang, X.X. Zhang, C.C. Dong, Scr. Mater. 63, 1024 (2010)

[14] B.P. Zhang, Y. Wang, L. Geng, C.X. Lu, Mater. Sci. Eng., A 539, 56 (2012)

[15] Y. Chino, T. Ueda, Y. Otomatsu, K. Sassa, X.S. Huang, K. Suzuki, M. Mabuchi, Mater. Trans. 52, 1477 (2011)

[16] Y. Chino, K. Sassa, X.S. Huang, K. Suzuki, M. Mabuchi, J. Jpn. Inst. Met. 75, 35 (2011)

[17] D.W. Kim, B.C. Suh, M.S. Shim, J.H. Bae, D.H. Kim, N.J. Kim, Metall. Mater. Trans. A 44, 2905 (2013)

[18] J.Y. Lee, Y.S. Yun, B.C. Suh, N.J. Kim, W.T. Kim, D.H. Kim, J. Alloys Compd. 589, 240 (2014)

[19] B. Langelier, A.M. Nasiri, S.Y. Lee, M.A. Gharghouri, S. Esmaeili, Mater. Sci. Eng., A 620, 76 (2015)

[20] M. Yuasa, N. Miyazawa, M. Hayashi, M. Mabuchi, Y. Chino, Acta Mater. 83, 294 (2015)

[21] J. Li, R.K. Mishra, A.K. Sachdev, Metall. Mater. Trans. A 43, 2148 (2012)

[22] T. Wang, L. Jiang, R.K. Mishra, J.J. Jonas, Metall. Mater. Trans. A 45, 4698 (2014)

[23] N. Stanford, Mater. Sci. Eng., A 528, 314 (2010)

[24] J. Bohlen, J. Wendt, M. Nienaber, K.U. Kainer, L. Stutz, D. Letzig, Mater. Charact. 101, 144 (2015)

[25] Z.R. Zeng, M.Z. Bian, S.W. Xu, C.H.J. Davies, N. Birbilis, J.F. Nie, Scr. Mater. 108, 6 (2015)

[26] Y.Z. Du, X.G. Qiao, M.Y. Zheng, K. Wu, S.W. Xu, Mater. Sci. Eng., A 620, 164 (2015)

[27] M. Yuasa, M. Hayashi, M. Mabuchi, Y. Chino, Acta Mater. 65, 207 (2014)

[28] L.B. Tong, M.Y. Zheng, L.R. Cheng, D.P. Zhang, S. Kamado, J. Meng, H.J. Zhang, Mater. Charact. 104, 66 (2015)

[29] J.Y. Lee, Y.S. Yun, W.T. Kim, D.H. Kim, Met. Mater. Int. 20, 885 (2014)

[30] H. Ding, X. Shi, Y. Wang, G. Cheng, S. Kamado, Mater. Sci. Eng., A 645, 196 (2015)

[31] P.M. Jardim, G. Solórzano, J.B.V. Sande, Mater. Sci. Eng., A 381, 196 (2004)

[32] J.C. Oh, T. Ohkubo, T. Mukai, K. Hono, Scr. Mater. 53, 675 (2005)

[33] E. Zhang, L. Yang, Mater. Sci. Eng., A 497, 111 (2008)

[34] W.Z. Chen, X. Wang, E.D. Wang, Z.Y. Liu, L.X. Hu, Scr. Mater. 67, 858 (2012) 
[35] Q. Yang, A.K. Ghosh, Acta Mater. 54, 5159 (2006)

[36] D. Wu, R.S. Chen, W.N. Tang, E.H. Han, Mater. Des. 41, 306 (2012)

[37] K. Tanaka, T. Mori, T. Nakamura, Philos. Mag. 21, 267 (1970)

[38] J. Li, R. Chen, Y. Ma, W. Ke, J. Magnes, Alloys 1, 346 (2013)

[39] B.Q. Shi, R.S. Chen, W. Ke, Mater. Sci. Eng., A 560, 62 (2013)

[40] X. Huang, K. Suzuki, A. Watazu, I. Shigematsu, N. Saito, Mater. Sci. Eng., A 488, 214 (2008)

[41] M.T. Kiser, F.W. Zok, D.S. Wilkinson, Acta Mater. 44, 3465 (1996)

[42] D.L. Shu, Mechanical Behavior of Engineering Materials, 2nd edn. (China Machine Press, Beijing, 2003), pp. 22-24. (in Chinese)

[43] H. Yan, T.R. Zhou, Principles of Metal Forming (Tsinghua University Press, Beijing, 2006), pp. 27-28. (in Chinese)
[44] W. Soboyejo, Mechanical Properties of Engineered Materials (Marcel Dekker Inc., New York, 2003), pp. 123-125

[45] J. Hu, Z. Marciniak, J. Duncan, Mechanics of Sheet Metal Forming, 2nd edn. (Butterworth-Heinemann, Oxford, 2002), pp. 3-4

[46] I. Toda-Caraballo, E.I. Galindo-Nava, P.E.J. Rivera-Díaz-delCastillo, Acta Mater. 75, 287 (2014)

[47] W.J. Kim, S.I. Hong, Y.S. Kim, S.H. Min, H.T. Jeong, J.D. Lee, Acta Mater. 51, 3293 (2003)

[48] Q. Wen, K.K. Deng, J.Y. Shi, B.P. Zhang, W. Liang, Mater. Sci. Eng., A 609, 1 (2014)

[49] L. Gao, R.S. Chen, E.H. Han, J. Alloys Compd. 481, 379 (2009) 